\title{
The influence of Social Networks in Suicidal Behavior
}

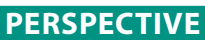

\author{
Bruno Gonçalves Leite ${ }^{1}$, Victoria Otoni Amorim ${ }^{1}$, Amanda Maria Costa Silva ${ }^{1}$, \\ Angelo Cantalice Freire da Silva', João Pedro Torres da Silva', Ákila Macêdo Freire', \\ Sonilde Saraiva Januário ${ }^{2}$, Daniela Cavalcanti e Silva Novais Carvalho2,
} Edglê Pedro de Sousa Filho ${ }^{2}$, Uilna Natércia Soares Feitosa², Emídio Antonio de Araújo Neto ${ }^{2}$, Susanne dos Santos Rocha ${ }^{3}$, Modesto Leite Rolim Neto ${ }^{1,2}$, Cícera Janielly de Matos Cassiano ${ }^{1}$

\section{Abstract}

Suicide is a serious public health problem worldwide in which they act influences multifactorial. We seek to clarify how social networks act on suicidal behavior. In this context, we conclude that the way in social networks interact with the risk factors determining how it can intervene in individual.

Suicide is a cause of death in which psychological factors are directly involved, as the individual ultimately forms a decisive intention to end their own life $[1,2,3]$. The suicidal downward spiral starts with ideation, which functions as an indicator of vulnerability and might lead to a suicide attempt or suicide. Suicidal ideation specifically involves thoughts about ending one's own life, from a range of general thoughts about death to more specific and elaborate ways to commit suicide. $[4,5]$ Suicidal ideation presents itself as one of the main predictors of suicidal risk, being used in many researches to estimate the presence of a suicidal process. [5]

Every year 800000 people die from suicide, with a rate of 11.4 per 100000. [6, 7] The WHO estimates that suicide represents $1.8 \%$ of the total global burden of disease and as such, suicide is a major, worldwide public health issue. [7] Borges et al. (2010) found that suicidal behaviors and their risk factors occur in the same prevalence and frequency for developed and developing countries. Social disadvantage and suicide might be associated due to several factors, such as higher incidence of mental disorders and lower access to medical care in such populations, even in developed countries. [8, 9]

While definitions of young adulthood vary, this period in the lifespan (approximately 18 to 35-40 years of age) is characterized by challenges regarding intimacy, occupation and lifestyle choices. [10, 11, 16]
1 Faculty of Medicine, Estácio -FMJ, Juazeiro do Norte, Ceará, Brazil.

2 Postgraduate Program in Health Sciences, FMABC, Santo André, São Paulo, Brazil.

3 Medicine and Specialties Dr. Emídio, Cajazeiras, Paraíba, Brazil.

Contact information:

Modesto Leite Rolim Neto.

”modestorolim@yahoo.com.br

Keywords

Suicidal Behavior; Risk Factors; Social Networks. 
Young adulthood is a crucial time for establishing one's professional and personal future, with effects on health in both the short and long term. [12, 16] Young people are at a particular risk of suicide, which represents the second leading cause of death in this age group. $[13,16]$ Globally, suicide attempts tend to decline with age; in France, the highest rates of suicide attempts are observed between ages 1519 years in women and between ages 20-25 years in men. $[14,16]$ Yet young adults are among the groups the least likely to seek care for psychological problems. $[15,16]$ For each completed suicide, it is estimated that 100-200 adolescents make nonlethal suicide attempts. [17, 18] Recent scientific evidences show that young people's suicidal behaviours (suicidal ideation and suicide attempts) are complex phenomena that seem to be rising, composing an important highlight of attention for social policies. $[19,5]$

Since the seminal sociological study by Durkheim in the late nineteenth century [20, 29], suicides have been studied for both sociology interests and public health reasons. In particular, Durkheim and later scholars pointed out that social isolation, also referred to as the lack of social integration, is a significant contributor to suicidal behavior. [20-23, 29] Roles of social isolation in inducing other physical and mental illnesses have also been examined. [24, 29] Conceptual models that inherit Durkheim's idea also claim that social networks affect general health conditions including tendency to suicide. [25-28, 29]

Although suicide is a weighty problem in public health worldwide, issues related to developing effective screening and preventive interventions are still unresolved. [30, 31] Researchers have sought to identify the risk factors associated with suicide that could provide targets for effective prevention program. [31]

Costa et Al [78], (2014) distribution risk factors previously determined in six Categories as follows: Risk factors associated with sociodemographic componentes; Risk factors associated with genetic com- ponents; Risk factors associated with Medicines and Drugs in general that interfere with bipolar disorder; Risk factors associated with Biological components; Risk factors associated with Psychological causes; and Risk factors associated with components of Religious and Spiritual. [78]

In the late 19th century, Emile Durkheim proposed that rates of suicide were partly associated with the extent to which individuals felt integrated with society and societal groups such as work and family. $[32,7]$ Durkheim proposed that a more dislocated society would lead to increased rates of suicide. More recent sociological accounts use network theory to specify the relationship between suicide and the 'presence or absence of interlocking social relationships'. [33, 7]

As Miller and Colleagues [18, pgs 286-287] note: 'The sociological theory of suicide, $[34,18]$ the psychache theory of suicide, $[35,18]$ and the interpersonal psychological theory of suicide (IPTS) [36-18] suggest that inadequate social support and strong interpersonal relationships increase risk for suicidal ideation and suicide attempts. The need to belong, in particular, is a central theme in Joiner's IPTS. These theories complement developmental research, which suggests that the maintenance of strong relationships with parents while concurrently establishing an independent network of close friends and close community connections (often within school settings) [37, 18] is needed for normative socioemotional growth.' Students with proper social support networks find it easier to develop coping strategies towards hostile situations. On the other hand, absent or weak social/family support often is often assumed as a higher suicide behaviour risk factor. [38-40, 5] Recent literature reviews conclude that perceived social support from parents and peers plays an important role in the development of adolescent Suicidal ideation and suicide attempts. [41, 18]

A mental health diagnosis is a strong predictor of suicidal behavior and nine out of 10 people who end their life will have experienced clinically signifi- 
cant mental health problems. [42, 3] One potential risk factor that has received comparatively little attention is the stigma associated with mental health problems and associated experience of discrimination. $[43,7]$ It has been suggested that the acceptance of stigmatizing beliefs about mental illness may influence levels of hopelessness. [44, 45, 7] For example, if individuals accept that they have a mental health problem, and internalize the often negative stereotypes associated with mental illnesses (e.g. dangerousness, chronicity), they will feel more hopeless and despairing of their future. Perceived racial discrimination and experience of acculturation in minority ethnic communities has been associated with increased risk of suicidal ideation $[46,47,7]$ and there are similar findings in the Lesbian, Gay, Bisexual and Transgender communities. [48, 49, 7]

More recently, studies have shown a relationship between diabetes and psychiatric disorders. In fact, a recent survey showed that the prevalence of depression is approximately $10 \%$ higher in diabetic patients. [50, 51]

Psychiatric and physical disorders, which are most commonly affective disorders, contribute to suicide risk. [52, 53, 31] Additionally, demographic factors, such as a lower household income, lower educational attainment, unemployment, and living alone $[54,55,31]$ as well as childhood maltreatment [56, 31] have been reported to be associated with increased suicide risk. [31] Demographic factors associated with suicidal ideation in univariate and most multivariate analyses were female gender, lower education, lower income, non-White ethnicity and Christian, non-Catholic religion. These variables are associated with social disadvantage in Brazil. [9]

However, these suggested risk factors may be insufficient to predict and prevent suicide because individual risk factors account for a small proportion of the variance in risk and lack sufficient specificity. $[57,31]$

Masuda N. et al. [29] (2013) define suicide ideation by the membership of a user to at least one community related to suicide. Then, we statistically compare users with and without suicide ideation in terms of users' properties including those related to egocentric networks.

In contrast, previous studies showed that suicidal behavior is less observed for individuals with more friends. [58, 59, 29] It has also been a longstanding claim that social isolation elicits suicidal behavior. [20-23, 29] As compared to typical users, some users may spend a lot of time online to gain many ties with other users and belong to many communities on the SNS. Such a user may be active exclusively online and feel lonely, for example, to be prone to suicide ideation. Although this is a mere conjecture, such a mechanism would also explain the strong contribution of the community number to suicide ideation revealed in our analysis. [29]

Media portrayals of suicide, in the news as well as entertainment media, have been associated with increases in suicide, particularly amongst the young. [60-64, 66] This phenomenon, known as suicidal 'contagion,' appears to be a short-term effect of exposure to stories in the media about persons committing or attempting suicide. $[65,66]$

One potentially influential online source of information about suicidal behavior of others is the widespread use of social networking sites. [66]

There are more than 100,000 websites that deal with methods of committing suicide. $[67,66]$ A recently conducted content analysis of the top 10 sites retrieved when searching about 'suicide' and 'suicide methods' found that the three most frequently occurring sites were pro-suicide. [68, 66] Many websites dealing with methods of committing suicide contain detailed descriptions of such methods, $[69,66]$ and also suicide notes, death certificates, and pictures pictures of people who have committed suicide. $[70,66]$ In these 'cybersuicides', individuals have committed suicide or carried out serious suicide attempts after obtaining information about suicide methods online. [71-75, 66] In a recent highly publicized case, a 24-year-old user of the 
site announced his intention to commit suicide and was later discovered to have completed the act. [76, 66] A review of the comments he received revealed that many of the discussants were sympathetic and offered advice to the troubled young person. However, there were others who encouraged the person to complete the act. Psychiatrists have also noted similar occasions with young people under their care. $[72,77,66]$

In individual, large variables act alone or not, to generate suicidal ideation. Hardy only one variable has a significant effect, and the action of a set of variables a potentiating factor for the development of suicidal behavior. In this context, social networks attenuating, so that access to social networks serve as social integration in order to have a greater proximity between users to avoid suicidal idea, as well as in other cases serve to encourage overcoming the feeling.

However, on-line networks can enhance the depressed state of the individual especially when there is a lack of social support: family, friends, school.
May increase the isolation of minorities facilitating the practice of prejudice and creates a situation where environment is hostile and favorable to the presence of "bullying". Several times some users even encourage suicidal practice, including teaching means to achieve success. (Figure 1).

By means of media, suicide becomes a condition that can easily be disseminated and therefore should be avoided publication. The internet, for example, is a virtual space where there is no possibility of establishing borders to control the activity of users, therefore, a snapshot through high spread and encouragement to suicide.

The results of the studies in the literature show that the risk factors associated with suicide exist and are relevant to clinicians and researchers. Therefore, research becomes important to maintain the high quality of knowledge of the disorder. In consequence, improve the screening and the possibility of intervention in patients with suicidal ideation.

Figure 1: Multi-influence of Social Network.






\section{References}

1. Johnson J, Gooding P, Tarrier N. Suicide risk in schizophrenia: explanatory models and clinical implications, The Schematic Appraisal Model of Suicide (SAMS). Psychol Psychother. 2008 Mar; 81(Pt 1): 55-77.

2. O'Connor RC, Nock MK. The psychology of suicidal behaviour. The Lancet Psychiatry.2014; 1(1): 73-85.

3. Owen R, Gooding P, Dempsey R, Jones S. A qualitative investigation into the relationships between social factors and suicidal thoughts and acts experienced by people with a bipolar disorder diagnosis. Journal of affective disorders. 2015; 176: 133-40.

4. Ferreira J, Castela M. Questionário de Ideação Suicida. In: Simões MR, Gonçalves MM, Almeida LS, editors. Testes e Provas Psicológicas em Portugal. Vol. 2. Braga: APPORT/SHO; 1999. p. 123-30.

5. Gonçalves A, Sequeira C, Duarte J, Freitas P. Suicide ideation in higher education students: influence of social support. Atención Primaria. 2014; 46: 88-91.

6. Preventing suicide: a global imperative WHO (2014). Disponível em: http://www.who.int/mental health/suicide-prevention/ exe summary english.pdf

7. Farrelly S, Jeffery D, Rusch N, Williams P, Thornicroft G, Clement $\mathrm{S}$. The link between mental health-related discrimination and suicidality: service user perspectives. Psychological medicine. 2015: 1-10.

8. Borges, G., Nock, M.K., Haro Abad, J.M., Hwang, I., Sampson, N.A., Alonso, J., Andrade, L.H., Angermeyer, M.C., Beautrais, A., Bromet, E., Bruffaerts, R., de Girolamo, G., Florescu, S., Gureje, O., Hu, C., Karam, E.G., Kovess-Masfety, V., Lee, E.K., Levinson, D., Medina-Mora, M.E., Ormel, J., Posada-Villa, J., Sagar, R., Tomov, T., Uda, H., Williams, D.R., Kessler, R.C. Twelve-month prevalence of and risk factors for suicide attempts in the World Health Organization World Mental Health Surveys. The Journal of Clinical Psychiatry. 2010; 71: 1617-1628.

9. Brunoni AR, Nunes MA, Lotufo PA, Bensenor IM. Acute suicidal ideation in middle-aged adults from Brazil. Results from the baseline data of the Brazilian Longitudinal Study of Adult Health (ELSA-Brasil). Psychiatry research. 2015; 225(3): 556-62.

10. Erikson E. In: Norton WW (ed) Childhood and society, New York; 1950.

11. Levinson $D$ et al. Seasons of a man's life. A.A. Knopf, New York; 1978.

12. Galland, O. Entrer dans la vie adulte : des e'tapes toujours plus tardives mais resserre'es. Economie et Statistique. 2000; 337(1): 13-36.

13. Hawton K, Saunders K, O'Connor R. Self-harm and suicide in adolescents. Lancet. 2012; 379(9834): 2373-2382

14. Beck F et al. Tentatives de suicide et pense'es suicidaires em France en 2010. Bulletin e'pide'miologique hebdomadaire. 2011; 47-48: 488-492.
15. Vanheusden K, van Lenthe FJ, Mulder CL, Van der Ende J, Van de Mheen D, Mackenbach JP et al. Patterns of association between alcohol consumption and internalizing and externalizing problems in young adults. J Studies Alcohol Drugs. 2008; 69(1): 49-57.

16. Dalglish SL, Melchior M, Younes N, Surkan PJ. Work characteristics and suicidal ideation in young adults in France. Social psychiatry and psychiatric epidemiology. 2015; 50(4): 613-20.

17. Mclntosh JL, Drapeau CW. U.S.A. suicide 2011: Official final data. Washington, DC: American Association of Suicidology; 2014.

18. Miller AB, Esposito-Smythers C, Leichtweis RN. Role of social support in adolescent suicidal ideation and suicide attempts. The Journal of adolescent health : official publication of the Society for Adolescent Medicine. 2015; 56(3): 286-92.

19. Saraiva CB. Estudos sobre o para-suicídio: o que leva os jovens a espreitar a morte. Coimbra: Redhorse, Indústria Gráfica; 2006.

20. Durkheim E. Suicide. New York: Free Press; 1951.

21. Trout DL. The role of social isolation in suicide. Suicide LifeThreatening Behav. 1980; 10: 10-23.

22. Joiner Jr TE, Brown JS, Wingate LR. The psychology and neurobiology of suicidal behavior. Annu Rev Psychol. 2005; 56: 287-314.

23. Wray M, Colen C, Pescosolido B. The sociology of suicide. Annu Rev Sociol. 2011; 37: 505-528.

24. Putnam RD. Bowling Alone. New York: Simon \& Schuster; 2000.

25. Pescosolido BA, Georgianna S. Durkheim. Suicide, and religion: toward a network theory of suicide. Amer Sociol Rev. 1989; 54: 33-48.

26. Bearman PS. The social structure of suicide. Sociol Forum. 1991; 6: $501-524$

27. Berkman LF, Glass T, Brissette I, Seeman TE. From social integration to health: Durkheim in the new millennium. Soc Sci Med. 2000; 51: 843-857.

28. Kawachi I, Berkman LF. Social ties and mental health. J Urban Health. 2000; 78: 458-467.

29. Masuda N, Kurahashi I, Onari H. Suicide Ideation of Individuals in Online Social Networks. PLoS ONE. 2013; 8(4): e62262.

30. Mann JJ, Apter A, Bertolote J, Beautrais A, Currier D, Haas A, et al. Suicide prevention strategies: a systematic review. JAMA 2005; 294 (16): 2064-74

31. Min JA, Lee CU, Chae JH. Resilience moderates the risk of depression and anxiety symptoms on suicidal ideation in patients with depression and/or anxiety disorders. Comprehensive psychiatry. 2015; 56: 103-11

32. Durkheim E. Le Suicide (English translation A. Spaulding and G. Simpson, 1951). The Free Glencoe: Illinois; 1951/1897.

33. Wray M, Colen C, Pescosolido B. The sociology of suicide. Annual Review of Sociology. 2011; 37, 505-528.

34. Durkheim E, Simpson G. Suicide, a study in sociology. Free Press; 1951. 
35. Shneidman ES. Suicide as psychache: A clinical approach to selfdestructive behavior. Jason Aronson; 1993.

36. Joiner TE. Why people die by suicide. Cambridge, MA, US: Harvard University Press; 2005.

37. Steinberg L, Morris AS. Adolescent development. J Cogn Educ Psychol 2001; 2: 55e87.

38. Walsh E, Eggert L. Suicide risk and protective factors among youth experiencing school dif囚 culties. Int J Ment Health Nurs. 2007; 16: 349-59.

39. Portzky G. Deliberate self-harm in young people: differences in prevalence and risk factors between The Netherlands and Belgium. European Child \& Adolescent Psychiatry. 2007; 17: 179-86.

40. Kuhlberg J, Peña J, Zayas L. Familism, parent-adolescent conflict, self-esteem, internalizing behaviors and suicide attempts among adolescent

41. King CA, Merchant CR. Social and interpersonal factors relating to adolescent suicidality: A review of the literature. Arch Suicide Res. 2008; 12: 181-96.

42. World Health Organisation. Suicide Prevention in Europe: The WHO European Monitoring Survey on National Suicide Prevention Programmes and Strategies. World Health Organisation, Geneva; 2012.

43. Rüsch $N$, Zlati $A$, Black $G$, Thornicroft $G$. Does the stigma of mental illness contribute to suicidality? British Journal of Psychiatry 2014; 205, 257-259.

44. Livingston J, Boyd J. Correlates and consequences of internalized stigma for people living with mental illness: a systematic review and meta-analysis. Social Science \& Medicine. 2010; 71, 21502161.

45. Sharaf AY, Ossman LH, Lachine OA. A cross-sectional study of the relationships between illness insight, internalized stigma, and suicide risk in individuals with schizophrenia. International Journal of Nursing Studies. 2012; 49, 1512-1520.

46. Gomez J, Miranda R, Polanco L (2011). Acculturative stress, perceived discrimination, and vulnerability to suicide attempts among emerging adults. Journal of Youth and Adolescence 40, 1465-1476.

47. Wang KT, Wong YJ, Fu CC (2013). Moderation effects of perfectionism and discrimination on interpersonal factors and suicide ideation. Journal of Counselling Psychology 60, 367378.

48. Clements-Nolle K, Marx R, Katz M (2006). Attempted suicide among Transgender persons. Journal of Homosexuality 51, 5369.

49. Cleary A (2012). Suicidal action, emotional expression, and the performance of masculinities. Social Science and Medicine 74, 498-505

50. Egede LE, Simpson K. Epidemiology, treatment and costs of depression in adults with Type 2 diabetes. Expert Rev Pharmacoecon Outcomes Res. 2003; 3(3): 251-262
51. Ceretta LB, Reus GZ, Abelaira HM, Jornada LK, Schwalm MT, Hoepers NJ, et al. Increased prevalence of mood disorders and suicidal ideation in type 2 diabetic patients. Acta diabetologica. 2012; 49 Suppl 1: S227-34.

52. Harris EC, Barraclough B. Suicide as an outcome for mental disorders. A meta-analysis. Br J Psychiatry 1997; 170: 205-28.

53. Hawton K, van Heeringen K. Suicide. Lancet 2009; 373(9672): 1372-81.

54. Lee HY, Hahm Ml, Park EC. Differential association of socioeconomic status with gender- and age-defined suicidal ideation among adult and elderly individuals in South Korea. Psychiatry Res 2013; 210 (1): 323-8.

55. Milner A, Page A, LaMontagne AD. Long-term unemployment and suicide: a systematic review and meta-analysis. PLoS One 2013; 8(1): e51333.

56. Miller AB, Esposito-Smythers C, Weismoore JT, Renshaw KD. The relation between child maltreatment and adolescent suicidal behavior: a systematic review and critical examination of the literature. Clin Child Fam Psychol Rev 2013; 16(2): 146-72.

57. Oquendo MA, Currier D, Mann JJ. Prospective studies of suicidal behavior in major depressive and bipolar disorders: what is the evidence for predictive risk factors? Acta Psychiatr Scand 2006; 114(3): 151-8.

58. Bearman PS, Moody J. Suicide and friendships among American adolescents; 2004.

59. Cui S, Cheng Y, Xu Z, Chen D, Wang Y. Peer relationships and suicide ideation and attempts among Chinese adolescents. Child Care Health Dev. 2010; 37: 692-702.

60. Hawton, K., \& Williams, K. Influences of the media on suicide. British Medical Journal. 2002; 325: 1374-1375.

61. Gould, M., Jamieson, P., \& Romer, D. Media contagion and suicide among the young. American Behavioral Scientist. 2003; 46: 1269-1284.

62. Gould, M. Suicide clusters and media exposure. In S.J. Blumenthal, \& D.J. Kupfer, Et al. Suicide over the life cylce: Risk factors, assessment, and treatment of suicidal patients. American Psychiatric Press. 1990; 517-532.

63. Pirkis, J., \& Blood, R.W. Suicide and the media. Part I: Reportage in nonfictional media. Crisis. 2001: 22, 146-154.

64. Stack, S.. Media coverage as a risk factor in suicide. Journal of Epidemiology and Community Health. 2003: 57, 238-240.

65. Westerlund, M., Schaller, S., \& Schmidtke, A. The role of massmedia in suicide prevention. In D. Wasserman, \& C. Wasserman, et al. Oxford textbook of suicidology and suicide prevention: A global perspective. Oxford: Oxford University Press. 2009: 515523.

66. Dunlop SM, More E, Romer D. Where do youth learn about suicides on the Internet, and what influence does this have on suicidal ideation? Journal of child psychology and psychiatry, and allied disciplines. 2011; 52(10): 1073-80.

67. Dobson, R. Internet sites may encourage suicide. British Medical Journal 1999; 319- 337. 
68. Biddle, L., Donovan, J.E., Hawton, K., Kapur, N., \& Gunnell, D. Suicide and the Internet. British Medical Journal. 2008; 336: 800-802.

69. Gallagher, K.E., Smith, D.M., \& Mellen, P.F. Suicidal asphyxiation by using pure helium gas. Case report, review and discussion of the influence of the Internet. American Journal of Forensic Medicine and Pathology. 2003; 24: 361-263.

70. Westerlund, M., \& Wasserman, D. The role of the Internet in suicide prevention. In C. Wasserman, \& D. Wasserman, (Eds), Oxford textbook of suicidology and suicide prevention: A global perspective. Oxford: Oxford University Press; 2009.

71. Alao, A.O., Yolles, J.C., \& Armenta, W. Cybersuicide: The Internet and suicide. American Journal of Psychiatry. 1999; 156: 1836-1837.

72. Becker, K., \& Schmidt, M.H. When kids seek help on-line: Chat rooms and suicide. Journal of the American Academy of Child and Adolescent Psychiatry. 2004; 43: 246- 247.

73. Janson, M.P., Alessandrini, E.S., Strunjas, S.S., Shahab, H., El-Mallakh, R., \& Lippmann, S.B. Internet-observed suicide attempts. Journal of Clinical Psychiatry. 2001; 62: 478.

74. Prior, T.I. Suicide methods from the Internet. American Journal of Psychiatry. 2004; 161: 1500-1501.

75. Thompson, S. The Internet and its potential influence on suicide. Psychiatric Bulletin. 1999; 23: 449-451.

76. Ries, B. Anatomy of an Internet suicide. 2010. Available from: http://www.thedailybeast.com/blogs-and-stories/2010-08-31 /reddit-suicide-how-the-internet-can-help-and-hurt/[last accessed 20 May 2011].

77. Becker, K., Mayer, M., Nagenborg, M., El-Faddagh, M., \& Schmidt, M.H. Parasuicide online: Can suicide websites trigger suicidal behavior in predisposed adolescents? Nordic Journal of Psychiatry. 2004; 58: 111-114.

78. Costa Lda S, Alencar AP, Nascimento Neto PJ, dos Santos Mdo S, da Silva CG, Pinheiro Sde F, et al. Risk factors for suicide in bipolar disorder: a systematic review. Journal of affective disorders. 2015; 170: 237-54

\section{Comment on this article:}
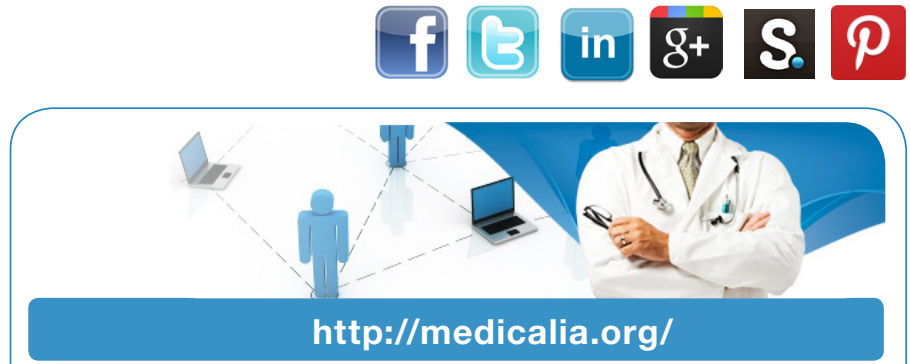

Where Doctors exchange clinical experiences, review their cases and share clinical knowledge. You can also access lots of medical publications for free. Join Now!

\section{Publish with iMedPub}

\section{http://www.imed.pub}

International Archives of Medicine is an open access journal publishing articles encompassing all aspects of medical science and clinical practice. IAM is considered a megajournal with independent sections on all areas of medicine. IAM is a really international journal with authors and board members from all around the world. The journal is widely indexed and classified Q1 in category Medicine. 